\title{
Patients with Rheumatoid Arthritis Have More Vulnerable Arterial Plaques, But Lowering Disease Activity May Stabilize This Threat
}

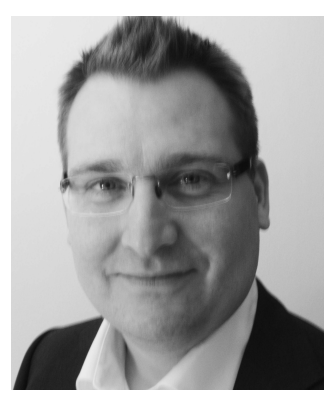

Patients with rheumatoid arthritis (RA) die of cardiovascular disease $(\mathrm{CVD})^{1}$. Although the inflammatory part of RA is better controlled with conventional and especially modern medicine, $\mathrm{CV}$ risk still seems to be double that of people without $\mathrm{RA}^{2}$. The risk of future CVD can be predicted by the presence of carotid artery plaques $(\mathrm{CP})$. If they are present, the risk for future acute coronary syndromes and stroke is increased 2- to 4-fold ${ }^{3,4}$. Moreover, as shown by Kobayashi and colleagues, CP seem to be more prevalent in $\mathrm{RA}^{5}$.

The presence of $\mathrm{CP}$ could prove helpful in identifying which RA patients are most at risk for future CV events. Additionally, it is shown that not only the presence of $\mathrm{CP}$ but also certain characteristics of these plaques are of great importance. A thin cap and less fibrous tissue inside plaques make them more vulnerable to rupture and more likely to cause CV events. Different types of CP have been identified together with their specific CV risk ${ }^{6}$. However, how does one reliably identify these vulnerable plaques? Simple eyeballing does not seem good enough. A more objective method could be measuring the gray-scale median (GSM). A lower score means less fibrous tissue and consequently a more vulnerable plaque. The usefulness of this GSM method in identifying vulnerable plaques has been shown by several authors 6,7 .

It is stipulated that the proinflammatory status in patients with RA causes more, and/or more vulnerable, plaques, explaining the elevated risk of CVD in RA. Therefore, Semb and colleagues investigated, in this issue of The Journal, the number of $\mathrm{CP}$ and the ultrasonic properties of these plaques in patients with $\mathrm{RA}^{8}$. And more importantly the authors looked at differences between patients with active RA, patients in remission, and non-RA controls.

With this fine study, Semb, et al make an interesting effort to show the reader that lowering disease activity could lower CV risk in RA. This latter is often stipulated and the opposite demonstrated ${ }^{9,10}$. However, to my knowledge this would be the first study providing evidence that lowering disease activity in RA is associated with more stable plaques and subsequently a lower $\mathrm{CV}$ risk.

Semb, et al studied 152 patients with RA, 45 from the Oslo RA register and 107 from the EURIDISS RA cohort. The usual demographic variables and information gathered during physical and laboratory examinations were collected. A special emphasis was made to determine the level of disease activity using several indices (i.e., Disease Activity Score 28, C-reactive protein, BSE, Simplified Disease Activity Index, and Clinical Disease Activity Index). As a control group, 89 randomly selected members of the general population matched for age, sex, and residential area were recruited. All 241 participants underwent ultrasound examinations of the carotid arteries, providing information on the intima-media thickness (IMT), the presence of plaques, and the size and GSM of plaques if present. These 241 participants were divided into RA patients with active disease, RA patients in remission, and non-RA controls. With the usual statistical calculations, adjusted for blood pressure and smoking, the number of $\mathrm{CP}$ per group and the plaque properties were compared.

The mean disease duration of the patients with RA was fairly long (17 years). As expected, the majority were female $(76 \%)$ and the median age was 63 years. Fully in line with expectations the investigators found that $\mathrm{CP}$ were more frequent in patients with RA than in controls, 1.2 plaques per RA patient versus 0.4 plaques per control. Further, although not statistically significant, the IMT in patients with RA seemed thicker than the IMT found in controls.

Although division into various disease activity groups did not provide a large number of statistically significant $p$ values, there was a clear trend showing more $\mathrm{CP}$ in the groups with higher disease activity. Moreover, the GSM of the plaques was lower in patients with active disease, indicating more vulnerable plaques. These results subscribe to the assumption that active disease with higher cytokine levels is associated with more and less stable plaques, which, in turn, is associated with more CV events.

See Carotid plaque and disease activity in RA, page 359 
There are several limitations to the study, ranging from minor to, in my view, 2 major shortcomings. On the minor side, there are technical imperfections that should be mentioned. No formal power calculation was done and blood samples were taken after a very short fasting period of only 3 hours. Further, although a normal practice, using a longitudinal measurement of a plaque to calculate a 3-D measure such as area of a plaque introduces some uncertainty.

Of more importance is the choice of the GSM as measure for stability of the plaques. Although GSM is fairly well investigated and the association with the incidence of future CVD reasonably well established, there are still many who question the robustness of this association. Further, other imaging modalities such as magnetic resonance imaging could prove (far) superior in discovering vulnerable plaques. Even though GSM may prove inferior in the future, the message of the present article is not diminished, and because ultrasound is noninvasive and very patient-friendly, one can understand the choice of GSM.

The most substantial problem one has reading the article by Semb, et al is the very large number of variables used in contrast to the small number of statistically significant findings. This has everything to do with the relatively small number of participants. When trying to correlate a widely variable measure like disease activity to a score like the GSM, the investigators should have realized they would have needed many more participants. This is especially true because disease activity was measured at only one point, and to counter the influence of coincidence that this single point is an outlier one needs large numbers. This is inherent to using a 1-point measure for the longterm burden of highly changeable variables such as disease activity.

Because of the small numbers, participants with diabetes were overrepresented in the RA group versus controls ( $9 \%$ vs $2 \%$ ) and this could not be statistically corrected for. Perhaps if the control group had been more substantial, the improvement in power would have provided more significant results. It is hard to believe only 89 controls could be recruited for the present study; a missed opportunity.

In an attempt to achieve more significant values the investigators tried different divisions of the RA group using various disease activity variables. This did not improve the readability of the article and especially the tables, perhaps even clouding the underlying important message.

Despite the shortcomings of the present study, its valuable conclusions should be clear. First, patients with RA have more $\mathrm{CP}$, which is associated with a higher risk for $\mathrm{CV}$ events. Second, plaques in patients with RA who are in remission are less vulnerable compared to plaques in patients with active disease. This latter finding is of great importance and emphasizes the necessity to aim for the lowest disease activity possible. Further, it warrants extra mindfulness of the $\mathrm{CV}$ risk in patients with (more) active RA. Finally, this could be the start of identifying patients with RA who are at greatest risk for $\mathrm{CV}$ events and trying to nullify this threat.

VOKKO P. VAN HALM, MSc, MD, PhD, Cardiologist, Department of Cardiology, Academic Medical Center,

Research Consultant, Department of Rheumatology, Jan van Breemen Research Institute - Reade, Amsterdam, The Netherlands

Address correspondence to Dr.Van Halm; E-mail: vpvanhalm@gmail.com.

\section{REFERENCES}

1. Kumar N, Marshall NJ, Hammal DM, Pearce MS, Parker L, Furniss $\mathrm{SS}$, et al. Causes of death in patients with rheumatoid arthritis: Comparison with siblings and matched osteoarthritis controls. J Rheumatol 2007;34:1695-8.

2. van Halm VP, Peters MJ, Voskuyl AE, Boers M, Lems WF, Visser $\mathrm{M}$, et al. Rheumatoid arthritis versus diabetes as a risk factor for cardiovascular disease: A cross-sectional study, the CARRE Investigation. Ann Rheum Dis 2009;68:1395-400.

3. Evans MR, Escalante A, Battafarano DF, Freeman GL, O'Leary DH, Del Rincon I. Carotid atherosclerosis predicts incident acute coronary syndromes in rheumatoid arthritis. Arthritis Rheum 2011;63:1211-20.

4. Li C, Engström G, Berglund G, Janzon L, Hedblad B. Incidence of ischemic stroke in relation to asymptomatic carotid artery atherosclerosis in subjects with normal blood pressure. A prospective cohort study. Cerebrovasc Dis 2008;26:297-303.

5. Kobayashi H, Giles JT, Polak JF, Blumenthal RS, Leffell MS, Szklo $\mathrm{M}$, et al. Increased prevalence of carotid artery atherosclerosis in rheumatoid arthritis is artery-specific. J Rheumatol 2010;37:730-9.

6. Mathiesen EB, Bonaa KH, Joakimsen O. Echolucent plaques are associated with high risk of ischemic cerebrovascular events in carotid stenosis: The Tromso Study. Circulation 2001;103:2171-5.

7. Biasi GM, Froio A, Deleo G, Piazzoni C, Camesasca V. What have we learned from the Imaging in Carotid Angioplasty and Risk of Stroke (ICAROS) study? Vascular 2004;12:62-8.

8. Semb AG, Rollefstad S, Provan SA, Kvien TK, Stranden E, Olsen IC, et al. Carotid plaque characteristics and disease activity in rheumatoid arthritis. J Rheumatol 2013;40:359-68.

9. Gonzalez-Gay MA, Gonzalez-Juanatey C, Pineiro A, Garcia-Porrua C, Testa A, Llorca J. High-grade C-reactive protein elevation correlates with accelerated atherogenesis in patients with rheumatoid arthritis. J Rheumatol 2005;32:1219-23.

10. Goodson NJ, Symmons DP, Scott DG, Bunn D, Lunt M, Silman AJ. Baseline levels of C-reactive protein and prediction of death from cardiovascular disease in patients with inflammatory polyarthritis: A ten-year followup study of a primary care-based inception cohort. Arthritis Rheum 2005;52:2293-9.

J Rheumatol 2013;40:348-9; doi:10.3899/jrheum.130104

Personal non-commercial use only. The Journal of Rheumatology Copyright (c) 2013. All rights reserved. 